\title{
Solar Based Smart Lawn Mower
}

\author{
R.S.Keote, Prasanna Kale, Chaitanya Raut, Bhaskar Samavedula, Rutuja Khawade, Abhijeet \\ Dumanwar
}

\begin{abstract}
Our lawn mower is a self grass cutting vehicle running on solar energy which avoiding obstacles, increases the capability of complete mechanized grass cutting devoid of any necessity of any human intervention. Our structure requires a couple of $12 \mathrm{~V}$ batteries to influence up the motors of the blades and for the movement. Lawn mowing is regarded as one of the most boring or tiring everyday jobs. It is also very reliable private robotic applications. The principle of this paper is to study and re-define the art in robotic lawn mowers to highlight the needs and capabilities of today's devices. A brief survey of available products, some patents and typical test bed prototypes are also provided. Some enabling techniques that make the vehicles more efficient are also suggested. We have utilized a solar board i.e. solar panel to charge the batteries the lawn mower and robot motors are interfaced to an Arduino Uno which governs the implementation of each motor. It is additionally used to interface an ultrasonic sensor for obstacle recognition and IR sensors for stopping the vehicle. The importance of this research lies in the presentation of an overview of a potential big market for personal vehicles.
\end{abstract}

Keywords: Grass-Cutter, Solar-panel, IR Sensor, Arduino Uno, DC Motor.

\section{INTRODUCTION}

The lawn mower is an aid in the major task of grass cutting. Due to the renaissance of green development in the current scene the companies with big regions are increasing the proportion of grass in the campuses and improved greenery triggers even more efforts and more money to tend to. In such cases, the grass cutter proves to be a god sent help. Due to rise of accessibility of structure on the chips and ICs, the lawn mower can be programmed very efficiently and also the decreased mass and price of DC motors sets off the vehicle to be independent of fossil fuels to be able to plug into

Revised Manuscript Received on April 25, 2020.

* Correspondence Author

Prof. R.S.Keote*, Department of Electronics and Telecommunication, Yeshwantrao Chavan College of Engineering, Nagpur, India, Email: rashmikeote@gmail.com

Prasanna Kale, Department of Electronics and Telecommunication, Yeshwantrao Chavan College of Engineering, Nagpur, India, Email: prasannapkale98@gmail.com

Chaitanya Raut, Department of Electronics and Telecommunication, Yeshwantrao Chavan College of Engineering, Nagpur, India, Email: 3chaitanya.fudge98@gmail.com

Bhaskar Samavedula, Department of Electronics and Telecommunication, Yeshwantrao Chavan College of Engineering, Nagpur, India, Email:bhaskarsamavedula1998@gmail.com.

Rutuja Khawade, Department of Electronics and Telecommunication, Yeshwantrao Chavan College of Engineering, Nagpur, India, Emailrutuja.khawade123@gmail.com:

Abhijeet Dumanwar , Department of Electronics and Telecommunication, Yeshwantrao Chavan College of Engineering, Nagpur, India, Email:abhijeet.dumanwar@gmail.com

(c) The Authors. Published by Blue Eyes Intelligence Engineering and Sciences Publication (BEIESP). This is an open access article under the CC BY-NC-ND license (http://creativecommons.org/licenses/by-nc-nd/4.0/) renewable energies. The presence of the Ultrasonic sensors and light dependent resistors in a minor and low-priced packaging cause the vehicle to be more responsive of its surroundings. By the presence of Arduino Uno, this controls the system, causes and increases in the module that can be added. Traditional design of lawn mowers had monitored powered engines which required very high maintenance like engine oil and lubricating. They moreover made a lot of noise as well as air pollution. In the chilly and severe atmosphere, the fossil-fuel powered motors are likely to freeze up and don't perform effectively. These drawbacks are overcome by means of electric motors. They are also very ecological for the reason that they are using solar-panels to charge-up. The mower uses battery-chorded system which causes a range as a limitation and may do some damage to the chords.

Intelligent robots are also a reality. Many of them are used today. Many more prototypes have been built. Some applications are: high-velocity spot-welding bots, accurate seam-welding machines, spray-painted robots moving around the contours of an automobile being, robots palatalizing variable size parcels, bot loading and unloading machines. The equipments of a smart robot are a manipulator, sensors and controller. However, it is mainly the architecture or the re-combination of these components and equipments, the paradigms programmed into the micro-controller, the foresight and super-smartness of the system designers, the practicality of the various prototype builders, the professionalism and focus on to the quality of the manufacturing engineers and technicians, and the prize which makes the vehicle very intelligent and more beneficial. The lawn mower industry has not seen any disruption in product development in the recent past. The advent of electric motors and small sized SoCs as motivated us to implement these development into lawn mower designs and also previous human effort and time is being lost doing a job which is naturally redundant. The usage of highly explosive materials in the regular household could cause house fire and other humanly losses. The hard to control nature of the engine was improved upon by the simplistic performance characteristic of the electric motor We wanted to save this human effort which could be put to better use.

\section{LITERATURE SURVEY}

In paper [1], a venture in which a self-figuring out tractor has been used. It's an automobile that can perform almost all the operations without or sometimes with minimum human support. The main benefits of this kind of computerized tractor in the discipline of agriculture are that it reduces the labour fee and time, besides that the main advantage is that it minimizes the human mistakes which similarly enhancements efficiency.

Published By:

Blue Eyes Intelligence Engineering \& Sciences Publication

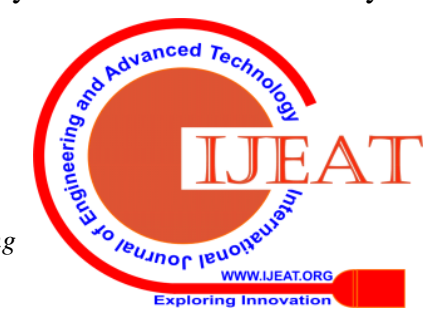


Numerous inventions are executed on this field, some of which were successful and encouraging and a few them were simply impractical for commercial implementation due a number of the drawbacks they had. Paper [2] has proposed computerized grass cutting system called as the 'Weed Eater' created by the Weed Eater Corporation. The cutter is without discharge sunlight based controlled that outfit's adequate capacity to work itself. It has a limit of cutting territories up to 13,500 sq-ft. It comprise of 34 glowing sun powered cells which are inserted on the frameworks stage. The framework works on a similar guideline as the Lawn Ranger aside from it utilizes a link underneath the outside of an individual's grass.

Paper [3] has depicted a Self-Efficient and Sustainable Solar Powered Robotic Lawn Mower. This paper proposes a self-ruling yard trimmer which is sunlight based controlled vision based automated garden cutter which will permit the buyer the capability to slash the grass with least endeavours. Unlike to the other vehicles, the automated grass trimmers in the market, this framework requires no edge cables to keep up the vehicle within the garden. Through a range of sensors the well-being takes significant thought in the gadget.

Paper [4] has portrayed about a programmed yard shaper which will assist the client with cutting the grass of their garden with negligible endeavours. Different sorts of sensors were utilized which would identify and stay away from any sort of obstructions coming their direction while cutting the grass and a microcontroller like AT super 16, LCD show, keypad. The primary goal of this programmed yard shaper is that the client will have the option to determine the territory that will be mown and furthermore the accuracy of the grass according to the prerequisite of the client with assistance of a keypad.

\section{PROPOSED SYSTEM}

The heart of the project is the design of the system. The Smart Solar Lawn Mower which is automated grass cutting vehicle running on solar energy. The main components used in the Lawn Mower are:

\section{A. Arduino Uno}

We used Arduino Uno in this robot in order to increase the modularity of the vehicle and also account for future modification. The major advantage of Arduino Uno is its capability to perform in such a small form factor. Also the programming language used for Arduino is $\mathrm{C}$, which is a very popular high

Technical specification of Arduino Uno:-
$>$ Microcontroller- AT mega 328
$>$ Operating voltage- $5 \mathrm{~V}$
$>$ Flash memory- $32 \mathrm{~kb}$
$>$ Clock speed $-16 \mathrm{MHz}$
Analog IN pins- 8 pins
$>$ PCB size- $18 \times 45 \mathrm{~mm}$
$>$ PCB weight -7 grams

\section{B. L293d9 Motor Driver}

This characteristic motor guider or motor-driver IC which allows two DC motors to be driven in either directions. L293D9 is a 16-pin IC which can control asset of 2 DC motors concurrently in any path. It means that you can control 2 DC motors in a single L293D9 IC.
Technical specifications:-

$$
\begin{aligned}
& >\text { Operating voltage- } 5 \mathrm{~V} \\
& >\text { Operating current }-3 \mathrm{Amps} \\
& >\text { Output current- } 1.2 \mathrm{Amps} \\
& >\text { Dimensions }-44 \times 37 \mathrm{~mm}
\end{aligned}
$$

\section{DC Series Motor}

The rate regulator works by changing the usual voltage sent to the motor. It could do this by merely correcting the power sent to the motor, but this an unproductive method. An enhanced method is to turn the motor supply ON and OFF very rapidly. If the switching is speedy enough, the motor functioning does not get affected; it only notices the typical consequence.

Technical specifications of DC Series Motor-

\begin{tabular}{|c|c|c|c|c|}
\hline $\begin{array}{l}\text { Sr. } \\
\text { No }\end{array}$ & Item name & Specifications & Quantity & Material used \\
\hline 01. & Blades & & 2 & Solid Steel \\
\hline 02. & Round rods & Diameter $1.5 \mathrm{~cm}$ & $3.6 \mathrm{ft}$ & $\begin{array}{l}\text { Polished } \\
\text { Stainless steel }\end{array}$ \\
\hline 03. & Ball-Bearings & $\begin{array}{l}\text { Outer Diameter } \\
2 \mathrm{~cm} \\
\text { Inner Diameter } \\
1.5 \mathrm{~cm}\end{array}$ & 4 & $\begin{array}{l}\text { Chrome } \\
\text { Steel }\end{array}$ \\
\hline 04. & Solar Panel & $35 \mathrm{~V}, 130 \mathrm{~W}$ & 1 & Silicon cells \\
\hline 05. & Switch/Button & - & 2 & Plastic \\
\hline 06. & $\begin{array}{l}\text { Electric Cable } \\
\text { wire }\end{array}$ & & $\begin{array}{c}7-8 \\
\text { meters }\end{array}$ & Copper \\
\hline 07. & Wheel & $10 \mathrm{~cm}$ Diameter & 4 & Rubbers \\
\hline 08. & Bolts & M 10 & 12 & Mild Steel \\
\hline 09. & Solar charger & $12 \mathrm{~V}$ & 1 & Plastic \\
\hline 10. & Nuts & M 10 & 12 & Mild Steel \\
\hline 11. & Battery & $12 \mathrm{~V}, 7 \mathrm{Ah}$ & 2 & $\begin{array}{l}\text { Lithium-ion } \\
\text { (Rechargeable) }\end{array}$ \\
\hline 12. & Motor & $12 \mathrm{~V} .700 \mathrm{RPM}$ & 2 & Magnetic Steel \\
\hline
\end{tabular}

$$
\begin{aligned}
& >\text { Operating Voltage- } 12 \mathrm{~V} \\
& >\text { Operating Current-80 mA } \\
& >\text { Operating Speed-700 rpm }
\end{aligned}
$$

List of various components used in Lawn Mower

Table 1. Various components used in Lawn Mower

\section{Calculations Required}

1. Force required by cutting blade to shear the grass is given by -

$$
\begin{aligned}
\mathrm{F} & =\text { Torque }(\mathrm{T}) / \text { Radius }(\mathrm{R}) \text { or diameter. } \\
& =0.1884 / 0.12=1.57 \mathrm{~N}
\end{aligned}
$$

Where, $\mathrm{T}=$ Torque of the Shaft, $\mathrm{R}=$ Radius of cutting blade $=120 \mathrm{~mm}$, Length $=240 \mathrm{~mm}$, Width $(\mathrm{W})=27 \mathrm{~mm}$, Mass $(\mathrm{m})=0.1600 \mathrm{~g}$.

But the shaft torque is given by;

$$
\mathrm{T}=\text { Weight }(\mathrm{wt}) * \text { Radius }(\mathrm{R})
$$$$
=0.1884 \mathrm{~N}-\mathrm{m}
$$

Electrical Power is given by;

$$
\mathrm{P} \text { (Power) }=(\text { Current }) \mathrm{I} * \mathrm{~V} \text { (Voltage rating)... }
$$$$
\mathrm{P}=130 \mathrm{~W}
$$

The motor's torque is given by;

$$
\begin{aligned}
& \mathrm{P}=2 * \mathrm{pi}^{*} \mathrm{~N} * \mathrm{~T} / 60 \ldots \ldots \\
& \mathrm{T}=(\mathrm{P} * 60) /\left(2 * \mathrm{pi}^{*} \mathrm{~N}\right) . .
\end{aligned}
$$

Angular velocity, $\mathrm{w}=2 * \mathrm{pi}^{*} \mathrm{~N} / 60=73.30 \mathrm{rad} / \mathrm{sec}$

Centrifugal force $=\mathrm{m}^{*} \mathrm{w}^{\wedge}(2)$

$* \mathrm{r}=103.1594 \mathrm{~N}$

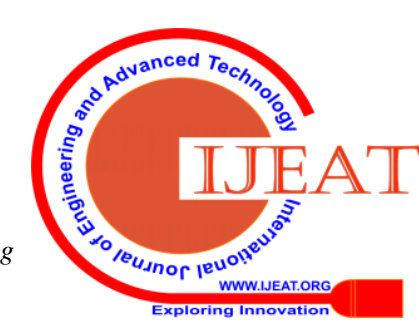


1.Forward velocity, $(\mathrm{v})=$ Forward distance covered/Time taken $=14.5 \mathrm{~m} / 50 \mathrm{sec}=0.29 \mathrm{~m} / \mathrm{sec}$

2. Approximate field coverage-

i. Battery voltage before operation $=22.9 \mathrm{~V}$

ii. Battery voltage after operation $=22.1 \mathrm{~V}$

iii. Voltage drop $=22.9-22.1=0.8 \mathrm{~V}$

iv. Expected V-Drop=6.8V

Hence, Voltage expected to be discharged from the battery = (22.9-6.8) $\mathrm{V}=16 \mathrm{~V}$

Therefore, Field Coverage $=(64 / 0.8) * 6.8=544$ sq-m

3. Field Efficiency $=\mathrm{EFC} / \mathrm{TFC}=0.129 / 0.00783=16.4750$

i. $\mathrm{EFC}=$ Total area covered $/$ Total time $=64 / 495=0.129 \mathrm{sq}$. $\mathrm{m} / \mathrm{sec}$

ii. TFC $=$ Forward Speed $(\mathrm{v}) *$ Width of the Blade $(\mathrm{W})=$ $0.29 * 27 * 10^{\wedge}(-3)=0.00783$

Battery has a capacity of 75Ah; it will get discharged in 1.02 hours as the current required is $70 \mathrm{~A}$.

The following diagram shows the flow chart and block diagram of smart solar lawn mower

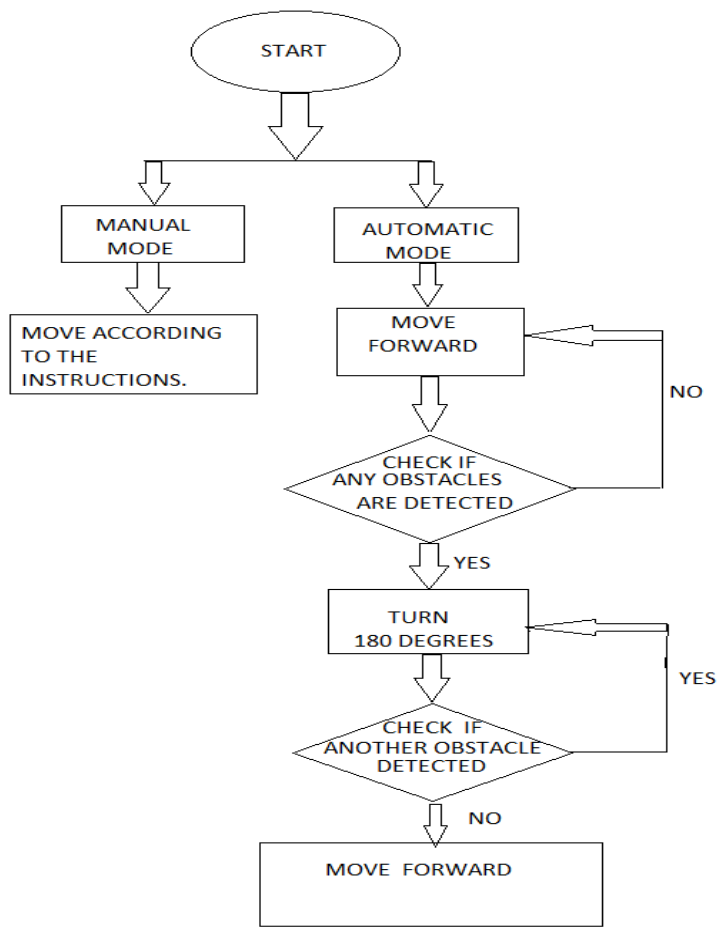

Figure 1. Flowchart showing the Various Modes of Operations

The Flowchart shown in Figure1 starts program execution with declaring and initializing all the pointers and memory locations. All the sensors are also initialized. When the machine gets started, first the mode is selected. Two modes are given the manual and the automatic mode. In the manual mode, the vehicle performs according to the instructions sent by the user. This can be done by a separate Bluetooth control module. In the auto mode, the lawn mower slowly starts to move as it is assumed that, at the start, no obstacle is present in front. Then after covering a certain distance, it checks if any obstacles are present. If no obstacles are present, then the vehicle continues to move forward with a constant velocity. If any obstacle is present, then first the vehicle makes a turn of 90 degrees, moves a little forward and then again rotates by 90 degrees (Total 180 degrees). It checks the obstacle condition again and continues to operate further ahead.

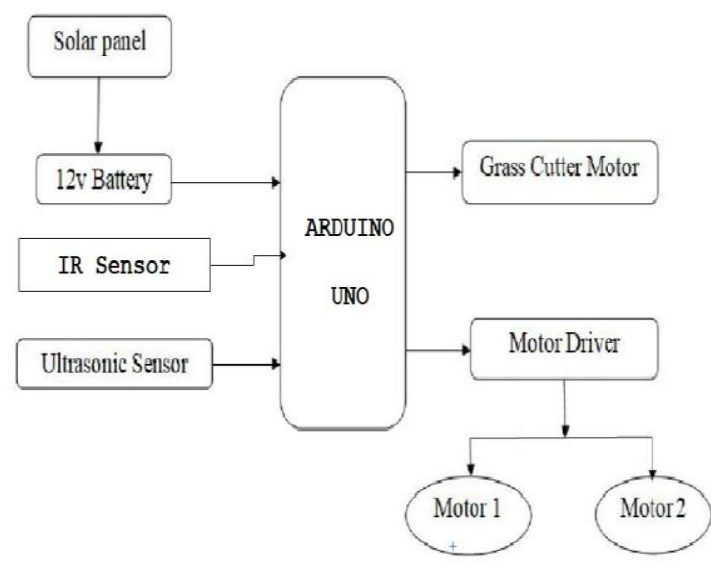

Figure 2. Block Diagram of Lawn Mower

The block diagram shown in Figure-2 contains a regular set-up of the main components. The Arduino Uno is held at the centre which is connected to the batteries of 12 volts and the infrared sensors. The batteries are connected to the solar panel. The ultrasonic sensors are also present which are again governed by the Arduino. On the other side, the grass cutter motor for the blade and two motors for the wheels are joined together with the model.

\section{WORKING}

In the circuit diagram as described in figure-3, the pin connections of all the components are narrated. The connections are made properly on the PCB (Printed Circuit Board) with suitable etching and soldering. It consists of the Arduino Uno (ATmega-328A) which has a total of 28 pins and contains the program developed to operate the vehicle. The main interfacing is carried out by the Arduino only as mentioned below. Pin 7 (+VCC) is connected to the power supply supplied through the batteries. The same is connected to the motor driver IC-L293D9 pin no. 8 which governs the motor of the wheels through the guidance or commands of the Arduino. The input pins 2, 3, 4 and 5 of the Arduino are $j$ to the pins 2, 3, 10 and 15 of the motor driver IC. The pins 3, 6 and 11, 14 are connected to the motors 1 and 2 respectively. All of its other pins are joined to the ground.

Pin no. 6 provides supply to the ultrasonic as well as the infrared (IR) sensor. Pins 11 and 12 are the input and output pins of the ultrasonic sensor through the Arduino respectively. Pin no. 22 is connected to ground of both the sensors. The pin 9 is connected to the blade motor. The pin 8 is the output pin of the IR sensors.

Coming to the functioning of solar lawn mower, it consists of a panel of group of silicon cells mounted on the top of structure in a peculiar arrangement such that the angle of inclination is 45 degrees and hence, it receives high intensity solar radiations with no trouble.The solar panel transform this solar energy into electric power. Circuit diagram is shown in Figure 3, below.
Blue Eyes Intelligence Engineering \& Sciences Publication

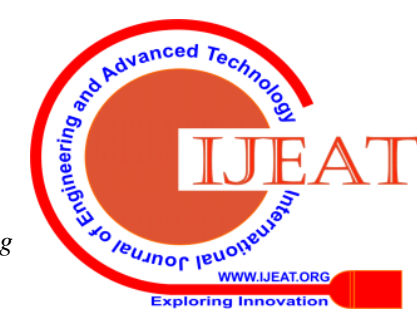




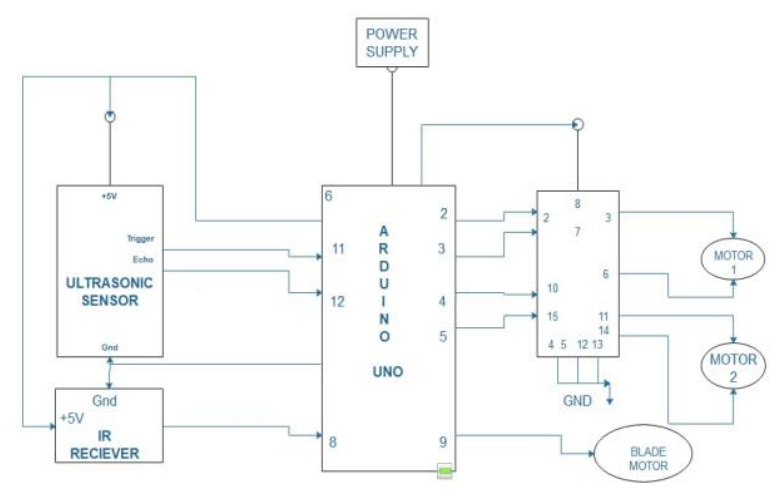

Figure 3. Circuit diagram

The major task of the solar charger is to increment the current from the board whilst batteries are getting charged; it also detaches the solar panels from the batteries after they are completely charged through the programmed code by Arduino Uno and also joins to the panels when the charging level in batteries is very low.

This electrical energy is collected in the batteries. Our motor is now connected to the batteries by way of linking wires and cables. The sharp blades induce the power from D.C. motor and which in turn triggers the blade and therefore rotary blades cut the lawn.

\section{RESULT AND DISCUSSION}

Our project titled "Solar Based Smart Lawn Mower" is completed successfully and the results obtained are satisfactory.

- It has faster cutting rate than the traditional mowers

- It can cut grass on areas with various dimensions

- Easy start by a button

- Stops efficiently by some IR sensors

- Easy charging

- Low noise and very less maintenance required

- Works in any conditions as it is weatherproof

- Mows the lawn in substantially less time.

The average height of the grass past using the mower was a smaller amount than the expected after the device have been to an elevation for the 4 different types of grass as mentioned above. Very less time-period was given for cutting the pasture. The total competence of the vehicle was observed to be $94 \%$ and the effective field coverage was about $1.11 \times 10^{-4}$ ha/hr.By appending characteristics of all the hardware apparatus utilized have been modified in it. The occurrence of each element has been purposed out and positioned cautiously, thus supplying to the most excellent working of our item. Subsequently, by using extremely unconventional ICs by means of the assistance of emerging technology, the project has been productively applied. Therefore, the project has been fruitfully designed and checked very well. This grass cutter will meet up the challenges of ecological creation and small cost of function as there is no price intended for fuelling. A grass cutter has been developed in support of the use of dwellings and other institutions which have turfs where tractor-driven cutters might not be applied.

\section{CONCLUSION}

The previous robotic systems were studied and a suitable design was made. The schematic for the same was made on which prototyping will take place. The components have been chosen based on design requirement and based on a few other parameters. Based on data collected from research papers, we made a few changes to make our design better. A timeline was made with the knowledge of the review dates and work has proceeded according to it. In the second review we have made a prototype model of the hardware and software system with a demonstration with ultrasonic and infrared sensor.

The prototype is on a metal sheet chassis and the detection was done using ultrasonic Sensor and the output was obtained. The green revolution has caused a burst in the lawn area and the requirement for a bot. Since cutting of grass is a big task requiring a lot of time; it is believed that human time should not be wasted on such tasks or at least reduced to the bare minimum. The cost effectiveness and the ease provided make the robot to be a necessity instead of a comfort device. The approach we use - that is, the Scottish-Yoke apparatus does not provide exceptional competence. This ability could be improved through another mechanism. And the motor velocity is reduced since we have used an item that is different and it can be replaced with a lighter material and the blade must be designed according to the type of grass. Our project essentially reaches out common folks because the lawn can be cut with minimal price plus minimal time. Ultimately, the scheme can be updated to get even better results by those who get inspired with this project.

\section{REFERENCES}

1. Pratik Patil, Ashwini Bhosale, Prof.SheetalJagtap, “Fully Automated Solar Grass Cutter", International journal of Science Technology and Engineering, Vol.3, Issue 9, May 2017.

2. Ernest L. Hall , "A Survey of Robot Lawn Mowers", Conference Paper in Proceedings of SPIE May 2014

3. Srishti Jain, Amar Khalore, Shashikant Patil, "Self Efficient andSustainable Solar Powered Robotic Lawn Mower", Vol.2, Dec2015.

4. Ashish kumarchaudhari, Yuvrajsahu, Prabhat kumar Dwivedi, HarshJain, "Experimental Study of Solar Power Grass Cutter Robot, MATS University Raipur, Chhattisgarh, India.

5. P.Amrutesh, B.Sagar, B.Venu, Mechanical engineering, MeRITS, A.P, India._"Solar Grass Cutter with Linear Blades by Using Scotch Yoke Mechanism"

6. Pratik Patil, Ashwini Bhosale, Prof.SheetalJagtap "Design and Implementation of Automatic Lawn Cutter" Department of Electronics \& Telecommunication Engineering, Brahmdevdada Mane Institute of Technology, Solapur, India.

7. Mrs. Melba D'Souza Ms.Vaidhavi B. NaikMs.Rucha V Bicholkar, "Automatic Solar Grass Cutter", IJSTE - International Journal of Science Technology \& Engineering | Volume 3 | Issue 12 | June 2017.

8. Tushar Baingane1, Sweta Nagrale2, Suraksha Gumgaonkar3, Girish Langade4, Shaila Ramteke5 Prof.V.M.Dhumal6, "Review on Fully Automated Solar Grass Cutter", International Research Journal of Engineering and Technology (IRJET) Volume 5, Issue 2, Feb 2018.

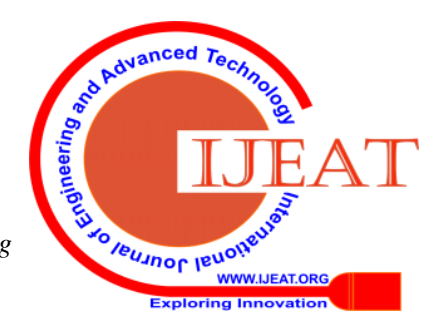




\section{AUTHORS PROFILE}

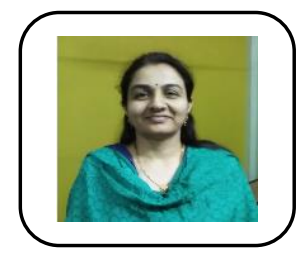

Rashmi Keote was born in India in 1979. She did B.E. in 2000 in Industrial Electronics Engg from Priydarshini College of Engg. and M.Tech in 2010 in Electronics Engineering from Yeshwantrao Chavan College of Engineering, Nagpur, India. She is currently perusing PhD from Rashtrasant Tukdoji Maharaj Nagpur University in YCCE as research Centre .Her area of research interests is Embedded system and VLSI circuits Design. Rashmi keote is currently working as Assistant Professor in Yeshwantrao Chavan College of Engineering since 2008. She has published total 13 research papers in international journals and international conference paper till date. She is lifetime member of ISTE, IAENG.

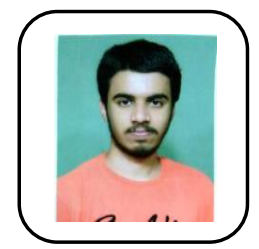

Prasanna P. Kale is a B.E., Electronics and Telecommunication Engineering (ETC) branch, final year student at Yeshwantrao Chavan College of Engineering, Nagpur, India.

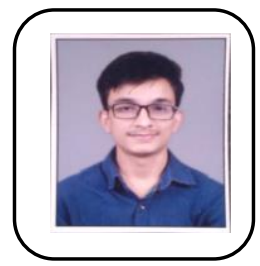

Chaitanya Raut is a B.E. Electronics and Telecommunication Engineering student at Yeshwantrao Chavan College of Engineering Nagpur, India

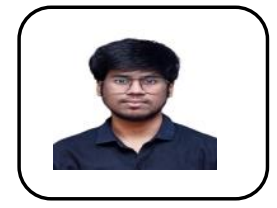

Bhaskar Samavedula is a B.E. Electronics and Telecommunication Engineering student at Yeshwantrao Chavan College of Engineering, Nagpur, India

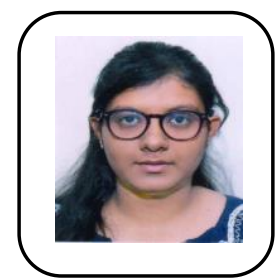

Rutuja Khawade is a B.E. Electronics and Telecommunication Engineering student at Yeshwantrao Chavan College of Engineering, Nagpur, India

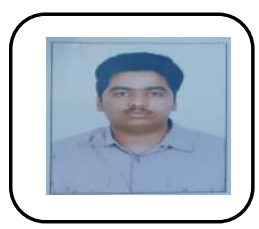

Abhijeet Dumanwar is a B.E. Electronics and Telecommunication Engineering student at Yeshwantrao Chavan College of Engineering, Nagpur, India

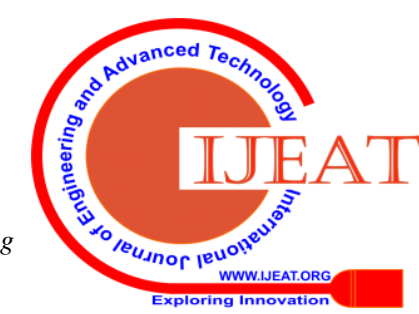

